\title{
A FAIXA CUPRÍFERA DO RIO GRANDE DO NORTE E PARAÍBA E AS RELAÇÕES DE CONTATO ENTRE AS FORMAÇÕES EQUADOR E SERIDÓ
}

\author{
Mário Tavares de O. Cavalcanti Neto \\ Geólogo, Prof. CEFET/RN, Unidade Sede, Pesquisador do Grupo Pesquisa Mineral \\ E-mail: mario@cefetrn.br
}

\section{RESUMO}

Uma Faixa mineralizada em Cobre $( \pm \mathrm{W}, \mathrm{Mo}, \mathrm{Au}, \mathrm{Ag}$ e $\mathrm{Bi})$ ocorre entre as Formações Equador e Seridó, a Leste do Antiforme da Serra das Umburanas, ocupando uma extensão não contínua de $54 \mathrm{Km}$ entre os Estados do Rio Grande do Norte e da Paraíba. Neste trabalho caracterizamos as relações de contato entre aquelas Formações do Grupo Seridó como típicas de ambiente sedimentar com contribuições básicas - ultrabásicas e propomos a inclusão desta Província Metalogenética Cuprífera entre as demais da Província Borborema.

PALAVRAS-CHAVE: Faixa Cuprífera, Província Metalogenética, Relações Estratigráficas, Mineralizações.

\section{THE COPPER BELT FROM RIO GRANDE DO NORTE AND PARAIBA STATES AND THE RELATIONSHIP OF CONTACT BETWEEN EQUADOR AND SERIDO FORMATIONS}

\begin{abstract}
A belt mineralized in copper $( \pm \mathrm{W}, \mathrm{Mo}, \mathrm{Au}, \mathrm{Ag}$ and $\mathrm{Bi}$ ) occurs between Equador and Seridó formations to East of Serra das Umburanas Anticlyne, occupying a non-continuous extension of $54 \mathrm{~km}$ between the Rio Grande do Norte and Paraíba states. In this study we characterized the relationship of contact between those formations of the Serido Group as typical of sedimentary environment with basic - ultrabasic contributions and propose the inclusion of this Copper Belt province among others from the Metallogenetic Borborema Province.
\end{abstract}

KEY-WORDS: Copper Belt, Metallogenetic Province, stratigraphy, mineralization. 


\section{A FAIXA CUPRÍFERA DO RIO GRANDE DO NORTE E PARAÍBA E AS RELAÇÕES DE CONTATO ENTRE AS FORMAÇÕES EQUADOR E SERIDÓ}

\section{INTRODUÇÃO}

Entre as Formações Seridó e Equador reconheceu-se uma extensa Faixa Mineralizada em Cobre e outros metais (W, Mo, Au, Ag e Bi) de, pelo menos, $54 \mathrm{Km}$ de extensão figura 1) não contínua, no flanco leste do antiforme regional da Serra das Umburanas, a qual denominamos de Faixa Cuprífera do RN-PB ou "RN-PB Copper Belt".

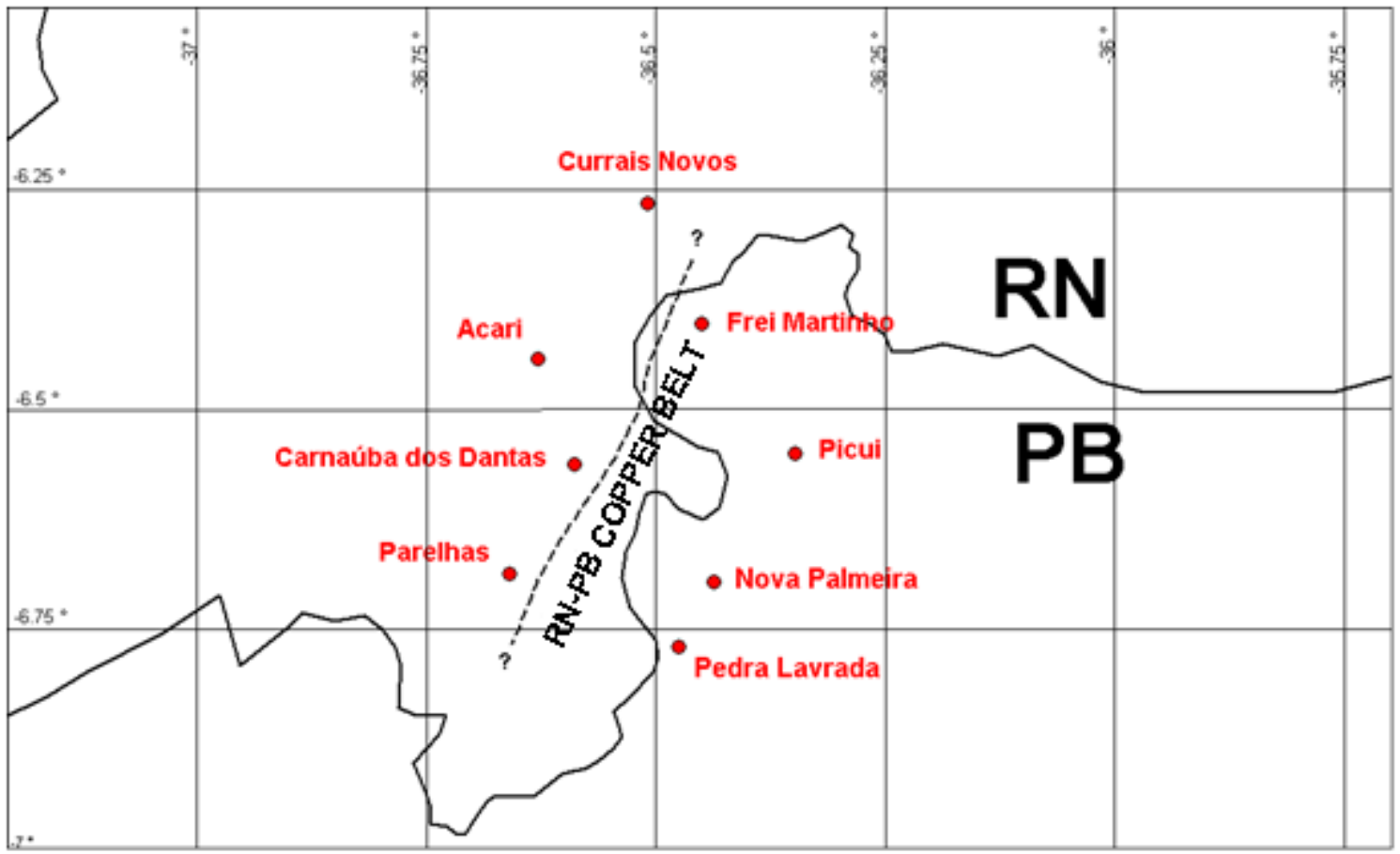

Figura 1: Mapa de Localização da Faixa Cuprífera do RN-PB (RN-PB Copper Belt).

Como as referências bibliográficas a respeito desta região são escassas, resolvemos publicar, a título de contribuição à Geologia desta Faixa, os resultados obtidos a partir de um intenso programa de Prospecção e Pesquisa Regional e de Detalhe executado pelo autor em parceria com várias empresas de Mineração. Este programa incluiu amostragem regional de sedimento de corrente, amostragem litogeoquímica (chip sample), mapeamento geológico de detalhe em algumas áreas selecionadas, desobstrução e mapeamento de serviços subterrâneos, geofísica e sondagem. Por força de Contrato de Confidencialidade algumas informações não puderam ser divulgadas neste trabalho.

\section{LITOLOGIAS DA ZONA DE CONTATO ENTRE AS FORMAÇÕES EQUADOR E SERIDÓ}

Na zona de contato entre as Formações Equador (base) e Seridó (topo) são reconhecidas, da base para o topo estratigráfico, as seguintes litologias resumidamente (e simplificadamente) descritas a seguir: 
Quartzito da Formação Equador - São quartzitos puros, micáceos, ocasionalmente conglomeráticos, constituindo o núcleo de um Antiforme Regional (Antiforme Serra das Umburanas), composto principalmente de quartzo (até $85 \%$ ), muscovita (15\%) e traços de óxido de ferro, sillimanita, plagioclásio e turmalinas pretas. A textura varia de granoblástica à granolepidoblástica e a principal estrutura é um bandamento primário definido por alternância de faixas mais ricas em quartzo com faixas mais ricas em muscovita.

Gnaisse - O Biotita-gnaisse é composto, essencialmente, de biotita ( 45\%), plagioclásio ( 20\%), quartzo ( 15\%), hornblenda (de 0 até 15\%), tendo como acessórios ( 5\%) óxido de ferro, epidoto e muscovita. A textura é heteroblástica, lepidonematoblástica, fina, uma vez que os cristais chegam ao máximo de $2 \mathrm{~mm}$. A estrutura predominante é o bandamento gnáissico, milimétrico, definido por alternâncias de faixas mais ricas em máficos (biotita e hornblenda) e faixas mais ricas em minerais claros (plagioclásio e quartzo).

Skarn - Os "Skarns" (também denominados de tactitos, escarnitos ou calciossilicáticas) constituem as rochas de maior interesse por conterem mineralizações de cobre, molibdenita, scheelita, prata, ouro e bismuto. Ocorrem em pelo menos quatro níveis geométricos distintos, intercalados no gnaisse, sendo o mais basal próximo às litologias mais quartzosas (biotita, muscovita xistos), e o mais superior próximo ao mica xisto Seridó.

A petrografia das calciossilicáticas é bastante complexa, pela diversidade de minerais. Destacamos como típicos desta Faixa a presença de minerais cobre (malaquita e calcocita), imprimindo à rocha a tonalidade esverdeada típica do cobre, diopsídio e epidoto. Outros minerais foram reconhecidos como a rodocrosita, minerais de bismuto e baixa presença de granada (grossulária?), visível a olho nu.

Uma forte componente cisalhante tardia é responsabilizada pela formação de skarns protomiloníticos, miloníticos e cataclasíticos e, provavelmente, pelo aporte de minerais de cobre + prata + ouro + bismuto. Esta fase tardia produziu também um fácies mais quartzoso do "skarn" e a associação Qz+Cu+Au com feldspato ocasional. O W e Mo também se relacionam a este processo. Destacam-se, entre os minerais visíveis a olho nú, o diopsídio $(40-60 \%)$, epidoto $(5-20 \%)$, vesuvianita $(0-10 \%)$, plagioclásio $(5-10 \%)$, quartzo (2$15 \%)$, hornblenda $(5 \%)$, actinolita/tremolita (1-15\%), bismuto $(0-25 \%)$, calcita $(0-3 \%)$, rodocrosita $(3-5 \%)$ e traços de scheelita, molibdenita, serpentina, talco (ensteatita), rodonita, granada (grossulária e/ou andradita), Sulfeto de ferro e minerais de cobre (calcocita e malaquita), eventualmente alterado para crisocola e óxido de ferro e clorita. Restrita a alguns corpos a pirita, calcopirita e bornita. A textura em geral é heteroblástica, predominantemente nematogranoblástica a granoblástica, estrutura maciça, às vezes bandada, cisalhada ou milonítica.

Xistos - Incluímos aqui os biotita-xistos correlatos à Formação Seridó e os "xistos máficos" da Faixa de Transição entre as Formações Equador e Seridó (ver adiante). Os primeiros são constituídos de biotita (65\%), plagioclásio (15\%), quartzo (10\%), granada (10\%), traços de cordierita, andalusita, sillimnita e óxido de ferro. A textura dominante é heteroblástica, lepidogranoblástica, média, raramente lepidogranoporfiroblástica, quando estão presentes os porfiroblastos de cordierita. Nas proximidades da base a cordierita e andalusita são raras, passando a abundante em direção ao topo da Formação Seridó. 
A estrutura principal é a xistosidade definida pela orientação das biotitas, secundariamente exibem micro-bandamento metamórfico, definida por faixas mais ricas em quartzofeldspato e faixas ricas em biotita, estruturas S-C de cisalhamento, sigmóides de cordierita com foliação interna, entre as principais. São comuns dobras assimétricas ("S" e "Z"), parasíticas, intrafoliais, sem raiz, apertadas e com planos axiais sub-verticais e eixos de "plunge" suave tanto para SSW como para NNE.

Ainda como "xistos" foram mapeados corpos com intercalações de anfibolitos, que obtiveram a denominação de campo (provisória) de "xistos máficos" devido ao alto teor de cromo. À olho nu os minerais são os mesmos descritos anteriormente, com maior presença de clorita (até 5\%), óxidos de ferro, algumas vezes calcocita e malaquita.

Anfibolitos - São corpos intercalados nos xistos máficos contendo anfibólios, principalmente hornblenda ( $50 \%)$, plagioclásio (10 a 20\%), diopsídio (0 a 20\%), Epidoto $(\sim 10 \%)$, clorita $(\sim 5 \%)$, biotita (0 a $5 \%)$, malaquita (0 a $5 \%)$, quartzo (3\%), Calcocita (0 a $3 \%)$, Actinolita-Tremolita ( 2\%), Scheelita $(0$ a $1 \%)$ e traços de rodocrosita, molibdenita, bismutinita e óxido de ferro. A textura é predominantemente heteroblástica, granonematoblástica, às vezes granoblásticas, com coloração esverdeada a verde escuro e estrutura variando desde maciça a bandada. $O$ ouro e a prata não são visíveis a olho nu.

Pegmatitos - Os pegmatitos da área, de acordo com sua estrutura interna, apresentam-se heterogêneos e homogêneos (conforme classificação de Johnston Jr., 1945). Os pegmatitos heterogêneosapresentando formas sub-circulares, desenvolvendo zonas e núcleos de quartzo (zona IV) e formas tabulares, estirados sub-paralelamente ao "trend" regional(melhor reescrever este parágrafo; está um pouco confuso)

Aqueles classificados como heterogêneo (zonados) desenvolvem um ou mais núcleos de quartzo (ou um único núcleo fragmentado?), composto essencialmente por quartzo de diversos tipos, entre os quais rosa, esbranquiçado a transparente, com raras muscovitas, algum feldspato (tanto K-Feldspato como plagioclásio), óxido de ferro e raros cristais de berilo (azul, verde??). Próximo ao contato com a encaixante (tanto nos quartzitos como nos xistos) identifica-se uma estreita zona rica em turmalinas pretas (turmalinito?), em massas e às vezes raros cristais prismáticos ( e no pegmatito ocorrem turmalinas negras com textura em pente - comb texture?). Essa faixa estreita contém ainda biotita, plagioclásio e quartzo. Em direção ao centro do corpo uma zona semelhante a um pegmatito homogêneo, rica em k-feldspato com textura gráfica (zona II), quartzo, muscovita, turmalina e óxido de ferro, seguida por outra zona, a maior volumetricamente, com cristais gigantes de feldspato potássico, muscovita e quartzo, traços de tantalita/columbita, berilo e óxido de ferro (zona III). Entre os pegmatitos heterogêneos explorados, nota-se que os serviços garimpeiros foram desenvolvidos nessa zona III, com banquetas próximas ao contato com os núcleos de quartzo, o que é comum em pegmatitos da região, pois a zona III é a mais importante economicamente, ocorrendo nela minerais como óxidos de $\mathrm{Ta}-\mathrm{Nb}$, berilos, turmalinas coradas, etc.

Os pegmatitos do tipo homogêneo são compostos de k-feldspato (65\%), quartzo (20\%), muscovita $(10 \%)$ e traços $(5 \%)$ de óxido de ferro, turmalina preta, apatita, berilo e tantalita/columbita. Exibem-se alongados, sub-paralelos ao "trend" e às vezes discordantes do "trend", provavelmente preenchendo falhas. A malaquita e calcocita aparecem em pegmatitos da região do Trigueiro. 


\section{RELAÇÕES DE CONTATO ENTRE AS FORMAÇÕES EQUADOR E SERIDÓ}

Entre as Formações Equador e Seridó foi reconhecida, do topo para a base, uma sequiência de litotipos mais ricos em biotita, passando gradativamente a tipos com biotita e muscovita (chamado pelos prospectores e mineradores da região de xisto ou gnaisse a duas micas), muscovita xisto até o muscovita quartzito característico da Formação Equador. Denominamos esta seqüência, provisoriamente, de Zona de Transição.

Lateralmente, em diferentes níveis estratigráficos desta Zona de Transição, unidades lenticulares, de dimensões variadas, de gnaisses às vezes com intercalações de calciossilicáticas (também chamadas de skarn, tactito e escarnito) e mármores são observadas. A geometria lenticular explica as seções geológicas onde se reconhece apenas gnaisse intercalado na Zona de Transição, outras seções onde o gnaisse intercala calciossilicáticas e ainda outras em que as calciossilicáticas e os mármores aparecem intercalados no gnaisse, em diferentes níveis geométricos, desde próximo ao quartzito Equador até próximo ao mica xisto Seridó e/ou ainda em posição intermediária entre essas Formações. Desta forma, em algumas seções geológicas, podem ser reconhecidas várias dessas sequiências calciossilicatadas, como na área entre a Mina Timbaúba e a Mina do Abreu, onde quatro níveis de escarnitos foram mapeados.

Naqueles locais onde não afloram os gnaisses com intercalações de calciossilicáticas e mármores e onde o contato entre as Formações Seridó e Equador não está obliterado por cisalhamentos e granitóides, o contato gradacional pode ser observado de forma mais inequívoca. Este aspecto foi observado em inúmeros perfis na borda Leste da Serra das Umburanas e da Serra da Timbaúba e em furos de sondagens. Citamos o perfil entre as coordenadas: $6^{\circ} 20^{\prime} 57^{\prime \prime}$ - $36^{\circ} 28^{\prime} 32^{\prime \prime}$ e $6^{\circ} 20^{\prime} 48^{\prime \prime}-36^{\circ} 28^{\prime} 08^{\prime \prime}$, para não citar pelo menos uma centena de perfis, onde esta gradação pode ser verificada.

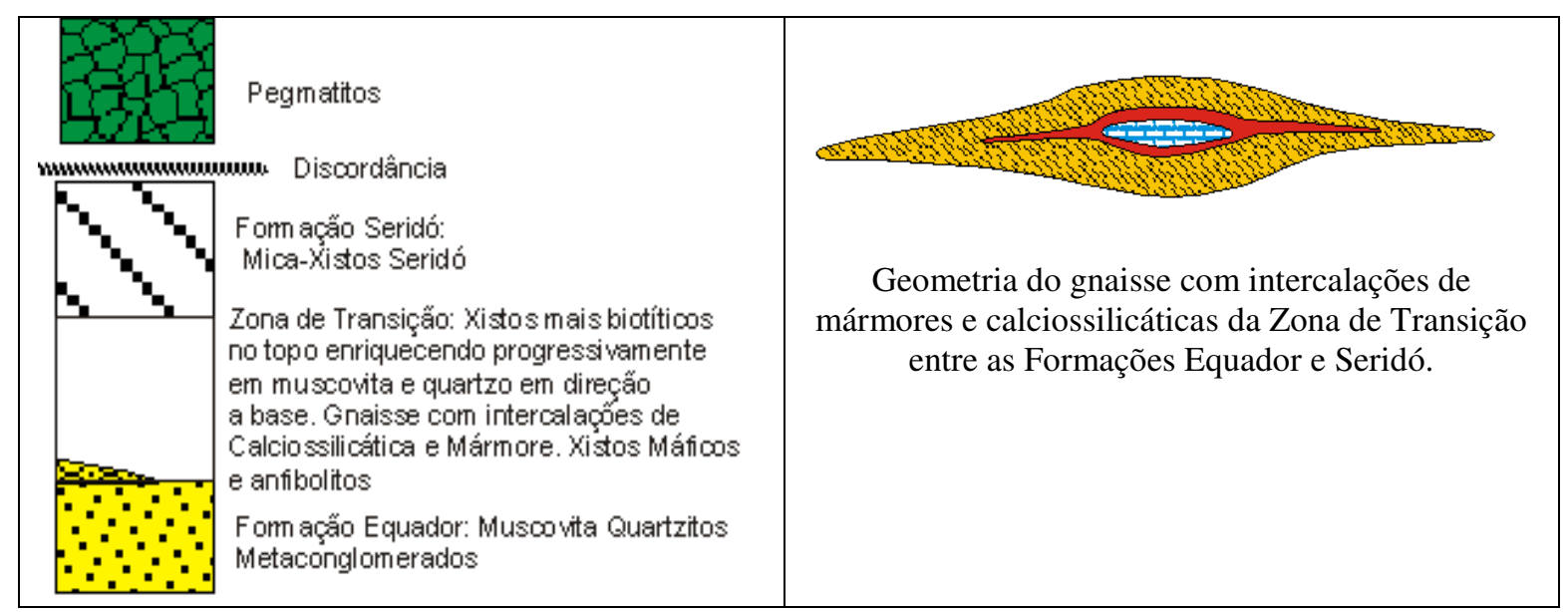

Figura 2: Estratigrafia da zona de contato entre as Formações Equador e Seridó na Faixa Cuprífera do RN-PB (RN-PB Copper Belt).

Outras litologias foram reconhecidas nesta Faixa de Transição entre as Formações Equador e Seridó, como xistos máficos (alto cromo) e anfibolitos, ambos mineralizados em $\mathrm{Cu}, \mathrm{W}$, $\mathrm{Mo}, \mathrm{Au}, \mathrm{Ag}$ e Bi. Nos locais observados (Xique-xique, Saco de Santo Antonio, Trigueiro, entre outros) essas unidades litológicas estão posicionadas nas proximidades da base do micaxisto Seridó. 
Desta forma, podemos concluir que o contato entre as Formações Equador e Seridó é do tipo gradacional, típico de ambiente sedimentar, refletindo um processo de mudança gradual desde o ambiente continental (ou de margem marinha), com quartzitos e metaconglomerados, até marinho profundo (mica-xisto Seridó) com aporte de meta básicas e meta ultrabásicas evidenciado pelos xistos máficos e anfibolitos. Entre esses extremos de plataforma continental e marinho profundo (abissal), uma seqüência de rochas, correlatas ao ambiente marinho mais raso, transformada em gnaisses, mármores e calciossilicáticas.

\section{AS MINERALIZAÇÕES DA FAIXA CUPRÍFERA DO RN-PB (RN-PB COPPER BELT)}

As mineralizações cupríferas estão hospedadas em escarnitos, anfibolitos, xistos máficos e, algumas vezes, nos gnaisses, sendo reconhecida desde a região dos Apertados em Currais Novos/RN até a região a sul da localidade de Trigueiro em Parelhas numa extensão de aproximadamente $54 \mathrm{Km}$.

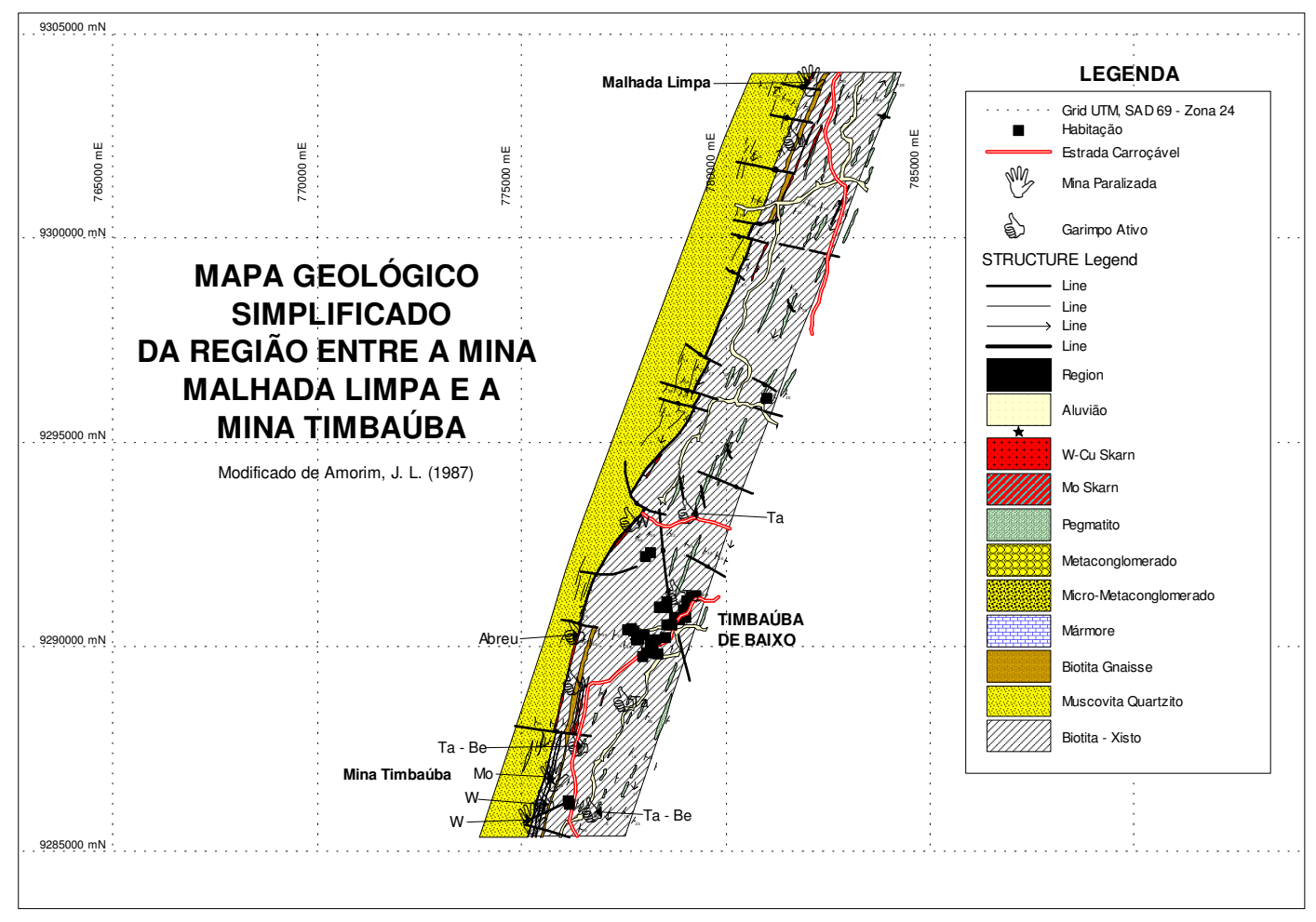

Figura 3: Mapa Geológico da Região entre a Mina Timbaúba e Malhada Limpa (adaptado de Amorim, 1987).

Na região da Mina Timbaúba ocorrem dois níveis mais contínuos de escarnitos de direção NNE/SSW, paralelos entre si e afastados aproximadamente $200 \mathrm{~m}$ um do outro (ver figura 4). O corpo mais a Oeste está mineralizado em $\mathrm{Cu}, \mathrm{W}$ e $\mathrm{Au}$ e foi aqui denominado de $\mathrm{Cu}$ skarn (ou W-Cu skarn), enquanto o corpo mais a Leste está mineralizado em Mo (molibdenita e powellita) e foi aqui denominado de Mo-skarn, inclusive com molibdênio pórfiro (ver figura 5). Mais dois níveis de escarnito, totalizando 4, foram reconhecidos nas intermediações da Mina do Abreu (ver figura 3). Aqui a mineralização cuprífera está hospedada principalmente em calciossilicáticas, secundariamente em gnaisses. O mineral 
de cobre é principalmente a malaquita produto de alteração de calcocita. Raramente se observam minerais como calcopirita, azurita, crisocola e bornita. $\mathrm{O}$ ouro, em pequenas quantidades (invariavelmente menor que $1 \mathrm{ppm}$ ), está associado ao cobre.

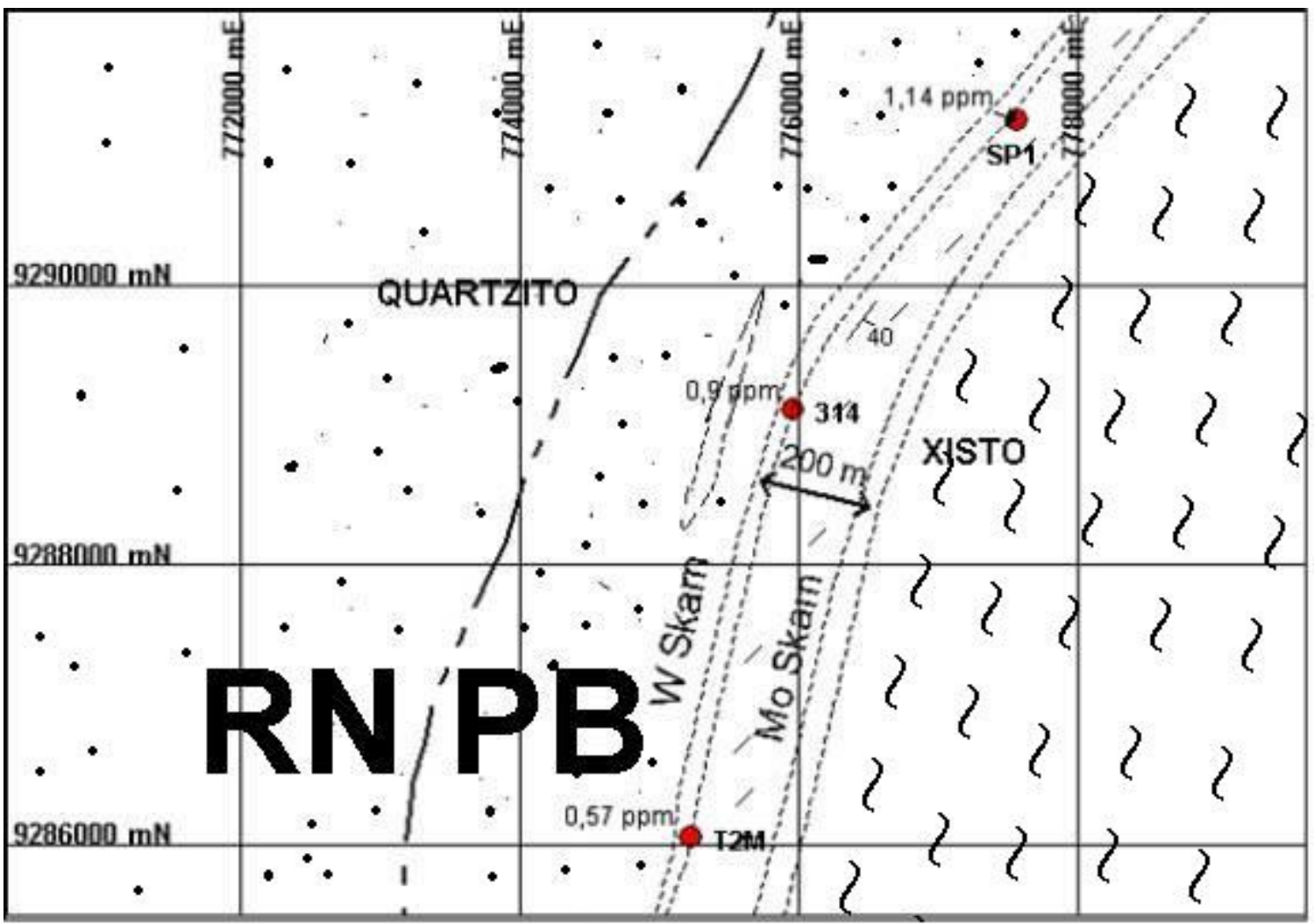

Figura 4: Esboço geológico da região da Mina Timbaúba, Frei Martinho/PB. Pontos vermelhos são amostras "chip sample" com teor de ouro em ppm.

No Mo-skarn não são observados teores significativos de W, Cu e Au. Por sua vez, não são encontrados teores de Mo dignos de menção no W-Cu skarn, sugerindo uma zonação metalogênica. Os pórfiros de mollibdenita e powellita (figura 5) e a possível zonação desta mineralização (figura 4) devem ser ressaltados pelas implicações em modelos metalogenéticos e geotectônicos.

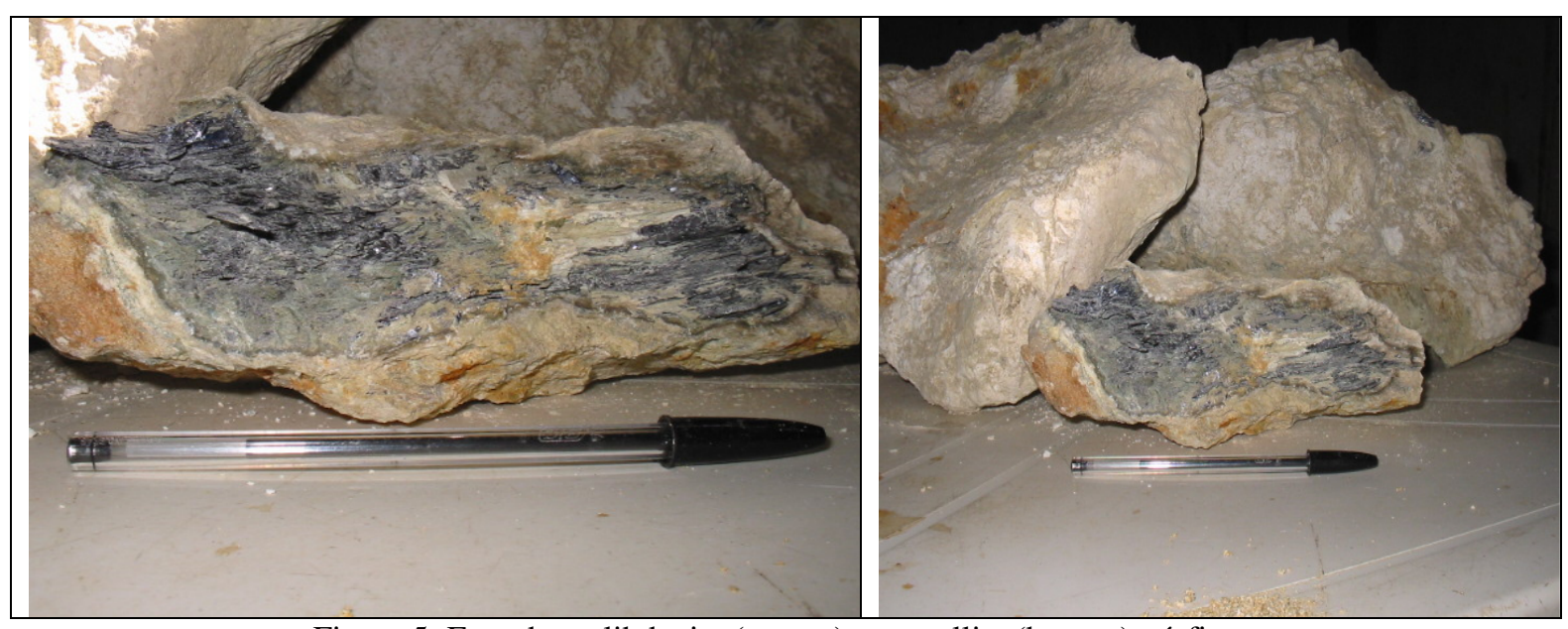

Figura 5: Foto de molibdenita (escuro) e powellita (branco) pórfiros. 
Ainda na região da mina Timbaúba foram mapeadas pelo menos 12 banquetas de acesso subterrâneo desenvolvidas por garimpeiros para exploração de scheelita em W-Cu skarn (ver figura 6). Todas desenvolvidas paralelamente ao "trend" NNE/SSW, às vezes seguindo o "plunge" da lineação $\mathrm{L}_{3} / / \mathrm{L}_{4}$. Nos locais mais ricos em cobre o garimpeiro paralisava suas atividades, pois na época, não se conhecia o potencial mercadológico de minerais cupríferos e os mesmos eram deletérios aos concentrados de scheelita.

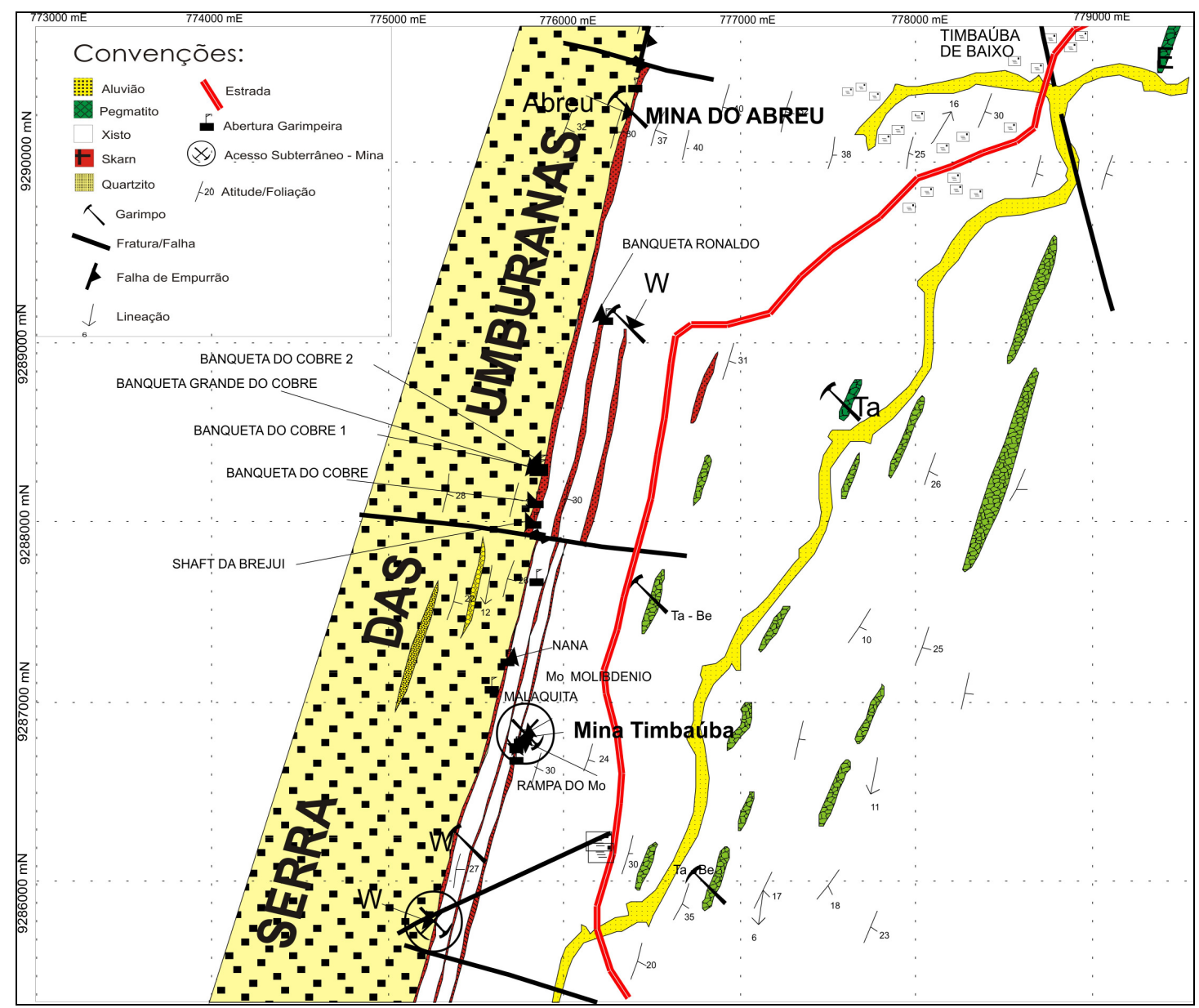

Figura 6: Mapa Geológico simplificado e de localização de banquetas de scheelita no W-Cu skarn.

Mais a Norte, na região dos Apertados por exemplo, os minerais de cobre nos escarnitos são a calcopirita (principalmente) e, secundariamente, a bornita e azurita. Não se observa a malaquita e nem a calcocita que caracteriza a mineralização a sul do paralelo $6^{\circ} 22^{\prime}$. Nesta região a lineação tem plunge para NNE, enquanto em Timbaúba o plunge é para SSW. Provavelmente, nos Apertados, a exposição do skarn é de um nível crustal mais profundo quando comparado àqueles skarn do sul.

Em Malhada Limpa a presença de minerais de cobre é rara. Próximo aos Apertados uma única amostra com ouro acima de 1 ppm (figura 4).

Em Xique-Xique, Ermo, Saco de Santo Antônio e Cobra, a Leste e Sudeste de Carnaúba dos Dantas, a mineralização cuprífera é encontrada em anfibolitos, e secundariamente nos xistos máficos, mineralizados em scheelita. Aqui se registra a presença de $\mathrm{Ag}$ e $\mathrm{Bi}$, além de um teor mais alto de cromo. $\mathrm{O}$ ouro permanece abaixo de $1 \mathrm{ppm}$. As tabelas 1 e 2 são listagens dos resultados de análises realizadas pela LAKEFIELD/GEOSOL de algumas amostras coletadas na região e que tiveram sua divulgação autorizada. 


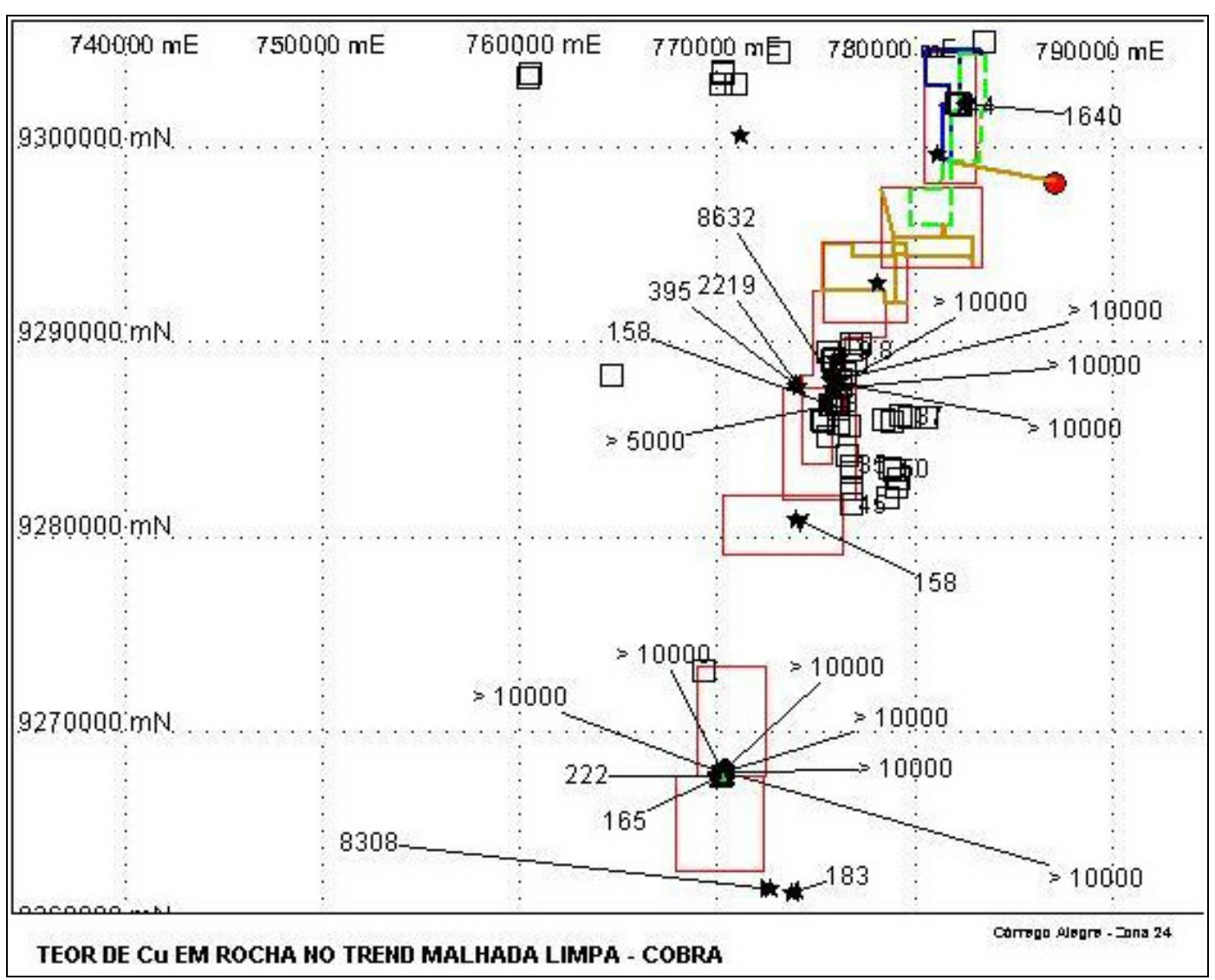

Figura 7: Litogeoquímica - Teor de Cobre (em ppm) numa porção da Faixa Cuprífera do RN-PB (RN-PB Copper Belt), entre a Mina Malhada Limpa e Cobra (Saco de Santo Antônio). Os limites de detecção de análise teor de $\mathrm{Cu}$ foram: 5.000 ppm numa campanha e 10.000 ppm em outra (pacote padrão da GEOSOLLakefield para 33 elementos)

TABELA 1: RESULTADOS DE ANÁLISES DE ALGUMAS AMOSTRAS

\begin{tabular}{|r|r|l|l|r|r|r|r|r|r|}
\hline Amostra & UTM E & UTM N & Description & Au & Ag & \multicolumn{1}{c|}{ Bi } & Co & \multicolumn{1}{c|}{ Cr } & \multicolumn{1}{c|}{$\mathbf{C u}$} \\
\hline 53 & 769770 & 9273596 & Skarn / amphibolite & 20 & $<5$ & 2,6 & 35 & $>5000$ & 1,1 \\
\hline 54 & 769804 & 9273584 & Skarn & 11 & $<5$ & 1,4 & 57 & 3039 & 1 \\
\hline 55 & 769953 & 9273607 & Calc silicate rock and quartz & $<1$ & 18 & 2,3 & 23 & 1074 & 0,91 \\
\hline 56 & 769775 & 9273692 & $\begin{array}{l}\text { Calc silicate rock has lenses,2- } \\
\text { 5mm thick }\end{array}$ & 1,5 & $<5$ & 0,52 & 30 & 3107 & 1,1 \\
\hline 1234 & 773815 & 9261722 & $\begin{array}{l}\text { Skarn em contato com } \\
\text { pegmatito }\end{array}$ & 8 & $<1$ & $<10$ & $<3$ & 16 & 183 \\
\hline 1235 & 772628 & 9261916 & Pegmatito rico em malaquita & 194 & 9.6 & 20 & $<3$ & 4.9 & 8308 \\
\hline 1236 & 775841 & 9287684 & $\begin{array}{l}\text { Rocha quartzosa rica em } \\
\text { malaquita (sub-solo) }\end{array}$ & 417 & 31 & 583 & $<3$ & 6.2 & $>10000$ \\
\hline 1237 & 775841 & 9287684 & Skarn epidotífero (sub-solo) & 967 & 16 & 1982 & 6.1 & 12 & $>10000$ \\
\hline 1238 & 775824 & 9288002 & $\begin{array}{l}\text { Rocha quartzosa rica em } \\
\text { malaquita (sub-solo) }\end{array}$ & 372 & 62 & 1100 & $<3$ & 5 & $>10000$ \\
\hline 1239 & 775824 & 9288002 & Skarn epidotífero (sub-solo) & 757 & 69 & 704 & 3.4 & 1.2 & $>10000$ \\
\hline 1240 & 770249 & 9267876 & Tailing & 288 & 98 & 6085 & 6.3 & 18 & $>10000$ \\
\hline 1241 & 774006 & 9280876 & $\begin{array}{l}\text { Skarn epidotífero com mineral } \\
\text { roxo desconhecido }\end{array}$ & $<5$ & 2.8 & 180 & 3.1 & 6 & 158 \\
\hline 1242 & 775841 & 9288116 & Skarn rico em pirita & 6 & 10 & 91 & 12 & 6.8 & 8632 \\
\hline
\end{tabular}


Na Mina Saco de Santo Antônio uma amostragem dos "tailings" de garimpeiros revelou teor de $\mathrm{Cu}$ de 2,6\% (ver tabela 2) e Ag aproximadamente $200 \mathrm{~g} /$ ton. O maior teor de ouro foi de $458 \mathrm{ppb}$. $\mathrm{O} \mathrm{Bi}$, acima de $5.000 \mathrm{ppm}$, parece estar associado aqui ao $\mathrm{Cu}+\mathrm{Ag} \pm \mathrm{Au}$. Nesta mina o minério é o anfibolito encaixado por xistos máficos, não sendo reconhecidos os escarnitos. Os minerais de cobre são principalmente malaquita produto de alteração da calcocita. Identificamos também a azurita e a crisocola.

\section{TABELA 2: RESULTADOS DE ANÁLISES DE ALGUMAS AMOSTRAS COM TEOR DE COBRE EM PERCENTAGEM}

\begin{tabular}{|r|r|l|l|r|r|r|r|r|r|}
\hline Am. & UTM E & UTM N & \multicolumn{1}{|c|}{ Descrição } & Au & Ag & Bi & Co & Cr & Cu (\%) \\
\hline 11328 & 770266 & 9267877 & $\begin{array}{l}\text { anfibolito quartzo/carb./anf./ } \\
\text { malaquita/bismutita(?) }\end{array}$ & 433 & 126 & 5409 & 4,4 & 20 & 2,6 \\
\hline 11329 & 770266 & 9267877 & $\begin{array}{l}\text { anfibolito quartzo/carb./anf./ } \\
\text { malaquita/bismutita(?) }\end{array}$ & 458 & 139 & 5353 & 5,3 & 41 & 2,1 \\
\hline 11330 & 770266 & 9267877 & anfibolito bandado & 274 & 138 & 3775 & 3,6 & 22 & 1,5 \\
\hline 11331 & 770266 & 9267877 & $\begin{array}{l}\text { Rocha cálcio-silicática (?), } \\
\text { silicosa, venulada }\end{array}$ & 164 & 74 & 2062 & $<3$ & 32 & 1,2 \\
\hline & & & $\begin{array}{l}\text { Rocha xistosa, esverdeada } \\
\text { (malaquita abundante), friável }\end{array}$ & 41 & 4,2 & 8006 & 20 & 97 & 2,3 \\
11332 & 770266 & 9267877 & \multicolumn{5}{c|}{ Au em ppb, Ag, Bi. Co e Cr em ppm. }
\end{tabular}

A maioria dos pegmatitos mineralizados em $\mathrm{Ta}, \mathrm{Nb}, \mathrm{Sn}, \mathrm{REE}, \mathrm{Li}, \mathrm{Be}, \mathrm{U} \pm \mathrm{Th}$ e às vezes $\mathrm{W}$ estão, via de regra, fora do contexto da Faixa Cuprífera do RN-PB. Entretanto, incluímos nesta Faixa pegmatitos mineralizados em $\mathrm{Cu}, \mathrm{Au}$ e $\mathrm{Ag}$, tais como aqueles da região de Trigueiros, Saco de Santo Antônio e Cobra.

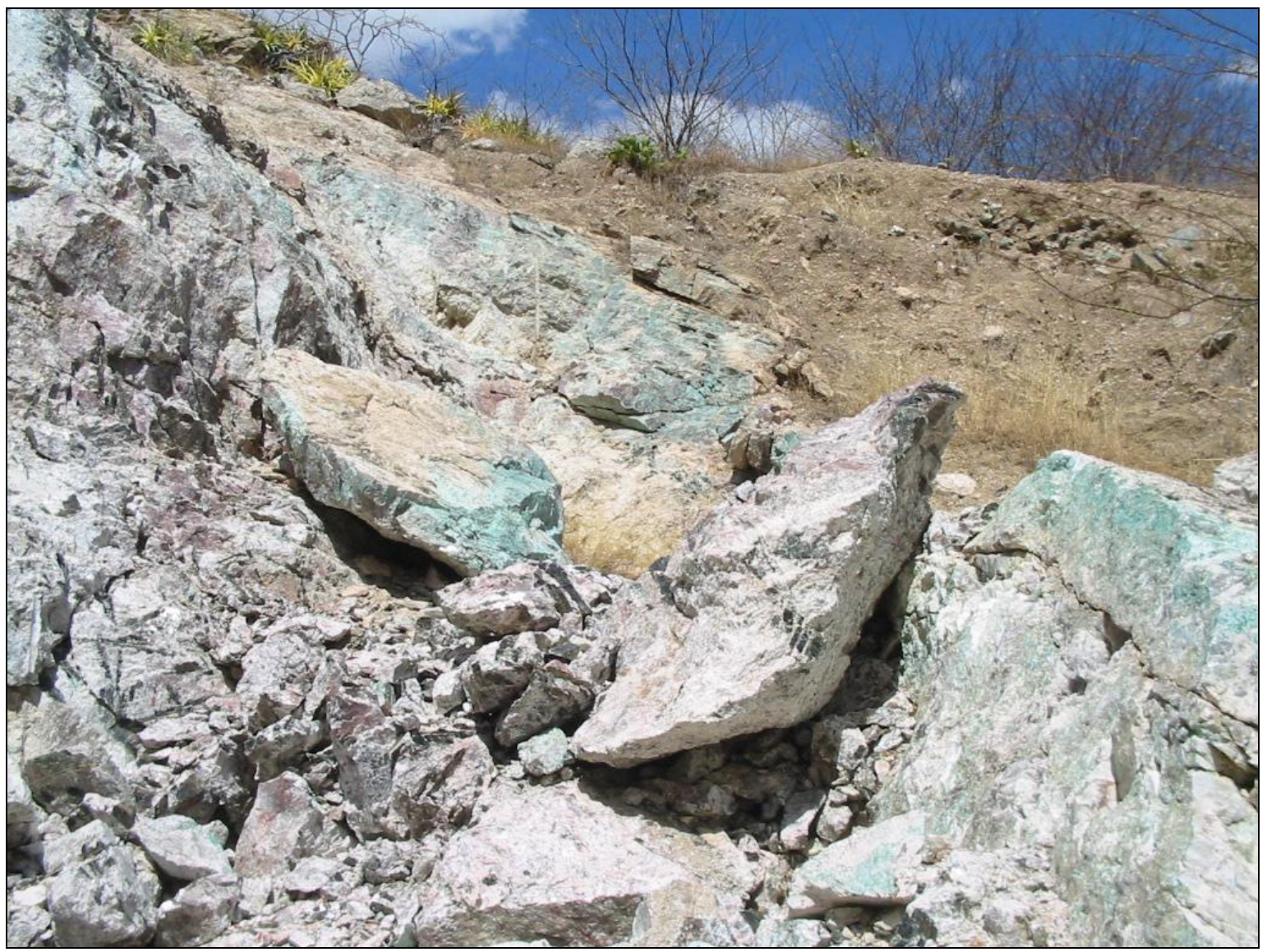

Figura 8: Pegmatito mineralizado em Cobre $(\mathrm{Au}+\mathrm{Ag})-$ Trigueiro, Parelhas/RN. 
Na região de Trigueiro (sul de Carnauba dos Dantas e Leste de Parelhas) são encontrados os pegmatitos cupríferos com $\mathrm{Au}+\mathrm{Bi} \pm \mathrm{Ag}$ (ver figura 8), além de trabalhos de garimpagem de ouro hospedado em anfibolitos ricos em cobre e encaixados por xistos máficos também mineralizados em $\mathrm{Cu}$. Atualmente a empresa Carnavalle, que adquiriu esta área da Emprogeo, realiza trabalhos de sondagem com resultados animadores.

Os processos mineralizantes superimpostos hidrotermais incluem a escarnitização regional e alterações do tipo potássica. Reconhecemos ainda processos de alteração propilítica, sericítica, saussurítica e argilítica subsidiariamente. O cisalhamento dextral ao longo do Antiforme da Serra das Umburanas pode ser apontado como o conduto para o aporte de fluidos mineralizantes.

\section{A FAIXA CUPRÍFERA DO RN-PB NO CONTEXTO DA GEOLOGIA REGIONAL}

Jardim de Sá e Salim (1980) subdividiram o Grupo Seridó em três Formações pertencentes a um mega-ciclo de sedimentação contínua, sem discordâncias regionais: Jucurutu (unidade inferior, formada de paragnaisses com intercalações de mármores e calciossilicáticas), Equador (unidade intermediária constituída de quartzitos com intercalações de meta-conglomerados e paragnaisses) e Seridó (unidade superior, dominante na região do Seridó, constituída micaxistos com intercalações subordinadas de mármores e calciossilicáticas). Jardim de Sá e Salim op cit e Jardim de Sá et. al. (1998) descrevem calciossilicáticas (gnaisses e mármores) em todas as Formações do Grupo Seridó (ver figura 9).

Archanjo e Salim (1986) propuseram outra subdivisão das supracrustais, separando dois Grupos: (i) O Grupo Jucurutu de idade paleoproterozóica que inclui a Formação Jucurutu basal, vulcanossedimentar e a Formação Equador, de topo, constituída de meta-sedimentos clásticos e (ii) o Grupo Seridó, de idade neoproterozóica, composto da Formação Parelhas na base (metaconglomerados) e a Formação Seridó (principalmente xistos) de topo. Os metaconglomerados marcariam o hiato desde o paleo ao neo proterozóico, apontada por Caby et. al. (1995) como a segunda inconformidade da Província Borborema, bem caracterizada na Faixa Seridó, separando um estágio rifting de uma sequiência predominantemente terrígena, semelhante a uma sucessão turbidítica, depositada em ambiente extensional por volta de $1 \mathrm{Ga}$.

No Mapa Geológico do Estado do Rio Grande do Norte, elaborado pela CPRM (2005), apenas as Formações Equador e Seridó têm representatividade na região aqui abordada. Apesar de ser bastante sugestivo e instigante a correlação entre a denominada Formação Serra dos Quintos (ver figura 9) com a Zona de Transição, onde se situa a Faixa de Cobre, deixaremos de fazê-lo devido a abrangência mais restrita deste trabalho e uma vez que não reconhecemos a Formação Jucurutu e nem a Formação Serra dos Quintos ao longo da Faixa Cuprífera do RN-PB aqui tratada.

O caráter gradacional observado a Leste da Serra das Umburanas entre os quartzitos e os xistos não dá suporte à inconformidade proposta por Archanjo \& Salim op cit. e Caby et. al. (1995) e sustenta a proposição inicial de Jardim de Sá e Salim (1980) e de Jardim de Sá et. al (1998) de uma evolução contínua e progressiva, pelo menos entre as Formações Equador e Seridó na região deste trabalho. 


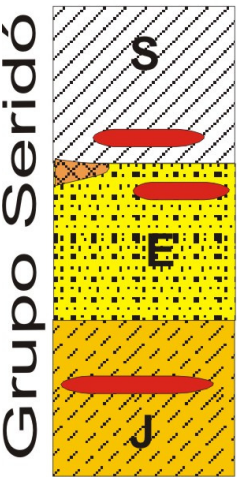

(a)

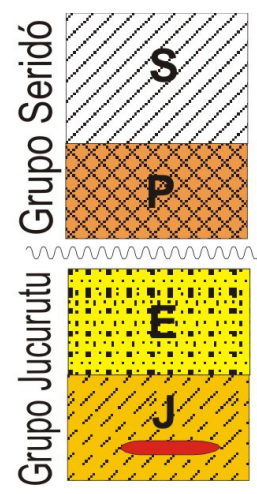

(b)

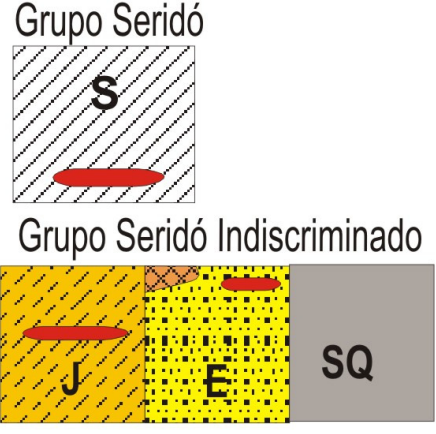

(c)

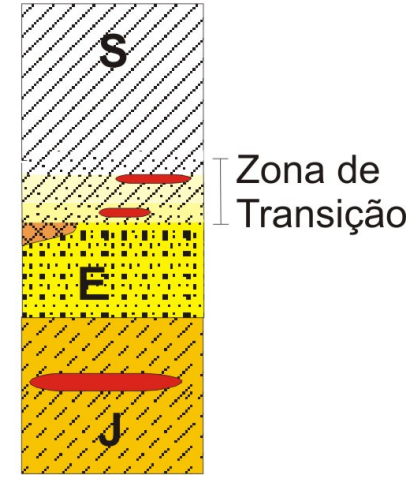

(d)

Figura 9: Colunas Estratigráficas propostas para o Grupo Seridó por (a) Jardim de Sá e Salim (1980) e Jardim de Sá et. al., 1998; (b) Archanjo e Salim, 1986; (c) pela CPRM, 2005 e (d) por este trabalho.

$\mathrm{S}=$ Formação Seridó; $\mathrm{E}$ = Formação Equador; $\mathrm{P}$ = Formação Parelhas; $\mathrm{J}$ = Formação Jucurutu; $\mathrm{SQ}$ = Formação Serra dos Quintos (as duas últimas não abordadas neste trabalho). Em cor vermelha representação de gnaisses com intercalações de mármores e calciossilicáticas, independente da sua relação estratigráfica.

Os gnaisses com intercalações de calciossilicáticas e mármores denominadas de "Seqüência do Major" por Cavalcanti Nt et al. (1988) em alusão a um setor de subsolo da mina Brejuí que explora o tactito "F" é restrito a esta Zona de Transição e reflete mudanças do ambiente marinho raso a profundo durante episódios de transgressão e regressão marinha. Acreditamos que o caráter gradacional desta zona e os diferentes níveis estratigráficos ocupados pela "Seqüência do Major" na Zona de Transição induziram alguns pesquisadores a posicionarem essa sequiência na base da Formação Seridó e/ou no topo da Formação Equador.

As zonações mineralógicas e texturais das calciossilicáticas em relação às encaixantes também apresentam características de origem sedimentar. Ocorrem tipos bandados mais ricos em anfibólio ( \pm pagioclásio \pm biotita) nas proximidades dos gnaisses e tipos mais granoblásticos, pobres em anfibólio e sem biotita, nas proximidades do mármore. Onde o mármore não aparece os tipos granoblásticos estão próximos ao núcleo do escarnito. $\mathrm{O}$ inverso ocorre naqueles tipos intercalados no mármore, no qual a porção de núcleo é nematoblástica, bandada. $\mathrm{O}$ protólito calciossilicatado, portanto, é de origem sedimentar (Cavalcanti Nt et al. 1988) fortemente afetado pelos processos hidrotermais superimpostos (Salim et. al. 1994) desencadeando reações típicas de "hidrotermalitos" que tendem a reagir e consumir as porções mais cálcicas.

As contribuições básicas e ultrabásicas necessitam de estudos mais detalhados para se compreender seu significado na evolução tectônica. A aparente concordância entre os xistos máficos e os anfibolitos é sugestivo de corpos estratiformes, com forte contribuição hidrotermal favorecida por zonas de cisalhamentos na interface do quartzito Equador e micaxisto Seridó.

\section{CONCLUSÕES E RECOMENDAÇÕES}

Ao reconhecermos uma Faixa Cuprífera no RN-PB, impõem-se comparações com os principais depósitos de cobre do mundo, como os relacionados ao tipo Zambian Copperbelt e os depósitos de Cobre Pórfiro. Os primeiros são descritos como uma combinação entre um modelo inicial estratiforme e reconcentrações stratabound epigenéticas (McGowan et. al. 2003), ambiente fluvial ou de margem marinha com conglomerados, arenitos, fluxos de detritos sub-aquosos conglomeráticos (inclui blocos exóticos), gabro, dolomito e quartzito 
formados durante uma fase rifting com aporte de fluidos magmáticos. As principais associações metalogenéticas são $\mathrm{Cu}, \mathrm{Co}, \mathrm{U}$ e secundariamente $\mathrm{Pb}-\mathrm{Zn}$, e Cobalto, Selenio, Prata e Ouro. A mineralização está hospedada em ardósias capeada por arenitos feldspáticos e arcóseos (Kampunzu e Cailteux 1999, Selley et. al. 2005, Wendorff 2005, Annels et al, 2004). Os depósitos de Cobre pórfiro, via de regra, estão associados à tectônica convergente, faixa polimetálica com associações $\mathrm{Cu}+\mathrm{Mo}+\mathrm{Ag}, \mathrm{Cu}+\mathrm{Zn}+\mathrm{Ag}$, forte e variada alteração hidrotermal associada à emplacement de plutons graníticos, inclusive escarnitização gerando os $\mathrm{Cu}$ skarns, hospedeiro de mineralização polimetálica (Redwood, 1999).

O "RN-PB Copper belt" não está devidamente estudado. Provavelmente por não terem sido encontradas, ainda, grandes reservas de cobre ao longo da Faixa. A corrida exclusiva à scheelita no passado pode também explicar esta negligência. As diferenças e semelhanças são grandes com os modelos cupríferos world-class, em termos de porte, grau metamórfico, associações metálicas, evolução geotectônica, potencial mineiro, entre vários outros aspectos.

A Zona de Transição caracteriza uma evolução contínua entre as Formações Equador e Seridó a partir de um ambiente com forte contribuição terrígena continental até marinho profundo, com a "Sequiência do Major" refletindo as condições intermediárias de mar raso e episódios de transgressão e regressões marinhas durante a evolução entre aquelas Formações. Um modelo rifting, já proposto por Caby et. all (1995), poderia explicar a transição descrita. Aos protólitos dos skarns aí formados se sobrepôs os processos de escarnitização regional e de forte hidrotermalismo responsável pela mineralização polimetálica e pela Faixa Cuprífera. À primeira vista o "RN-PB Copper belt" parece se assemelhar mais com as descrições dos Depósitos de Cobre Pórfiro, entretanto necessitam de estudos para uma melhor compreensão e conclusão a respeito.

\section{REFERÊNCIAS BIBLIOGRÁFICAS}

AMORIM, J. L. Geologia dos Depósitos de Tungstênio / Molibdênio da Região de Malhada Limpa e Timbaúba - RN / PB. Rel. de Grad. DG-UFRN, 232 p. 1986.

ANNELS A. E., VAUGHAN D. J., CRAIG J. R. Conditions of ore mineral formation in certain Zambian Copperbelt deposits with special reference to the role of cobalt. Mineralium Deposita, Springer Berlin / Heidelberg Volume 18, Number 1 . 2004

ARCHANJO, C. J. ; SALIM, J. . Posição da Formação Seridó no contexto estratigráfico regional (RN-PB). João Pessoa: Sociedade Brasileira de Geologia - Núcleo Nordeste. Anais do XII Simpósio de Geologia do Nordeste, 1986.

CABY, R., ARTHAUD, M. H., ARCHANJO, C. J. Lithostratigraphy and petrostructural characterization of supracrustal units in the Brasiliano belt of Northeast Brazil: geodynamic implications. Journal of South American Earth Sciences Volume 8, Issues 3-4, July-October 1995, Pages 235-246, 1995.

CAVALCANTI Nt, M. T. O. , JARDIM DE SÁ, M. E. F.; SALIM, J. Geologia da Faixa da Mina Brejuí, Currais Novos/RN: Reavaliação de Dados. In: XXXV Congresso Brasileiro de Geologia, v. 7. p. 2772-2774, 1988. 


\section{CPRM - MAPA METALOGENÉTICO PREVISIONAL DOS RECURSOS MINERAIS} DO ESTADO DO RIO GRANDE DO NORTE, 2005

JARDIM DE SÁ E.F. \& SALIM J. Reavaliação dos conceitos estratigráficos na região do Seridó (RN-PB). Miner. Metal., 80 (421): 16-28. 1980.

JARDIM DE SÁ, E.F.; MATOS, R.M.D.; OLIVEIRA, D.C.; RÊGO, J.M.; MONTEIRO, E.T.; DANTAS, J.R.A. Mapa Geológico do Estado do Rio Grande do Norte, escala 1:500.000. DNPM/UFRN/PETROBRAS/CRM, 1998.

Johnston Jr., W.D. 1945. Os pegmatitos berilo-tantalíferos da Paraíba e Rio Grande do Norte, no Nordeste do Brasil.DNPM/DFPM (Boletim 72). Rio de Jneiro, 85p.

KAMPUNZU, A. B. \& CAILTEUX, J. Tectonic Evolution of the Lufilian Arc (Central Africa Copper Belt) During Neoproterozoic. Pan African Orogenesis Gondwana Research, Volume 2, Issue 3, July 1999, Pages 401-421, Belgium, 1999.

McGOWAN, R. R., ROBERTS, S., FOSTER, R. P., BOYCE, A. J., COLLER, D. Origin of the copper-cobalt deposits of the Zambian Copperbelt: An epigenetic view from Nchanga. Geology; v. 31; no. 6; p. 497-500; Geological Society of America June 2003

REDWOOD S. D., The Geology of the Antamina Copper Zinc Skarn Deposit, Peru. Inmet Mining Corp., G. A. C. Mineral Deposits Division, 1999.

SALIM J., VERKAEREN J., GIULIANI G. Alteração Hidrotermal dos Skarns da Mina Brejuí, Currais Novos (RN) In: XXXVIII CONG. BRAS. GEOL., CAMBURIU (SC), 1994, v. 4. p. 279.1994.

SELLEY, D., BROUGHTON, D., SCOTT, R.J., HITZMAN, M., BULL, S.W. LARGE, R.R., McGOLDRICK, P.J., CROAKER, M. POLLINGTON, N A New Look at the Geology of the Zambian Copperbelt. Society of Economic Geologists, Inc., 100th Anniversary Volume. ISSN 0361-0128, 2005.

WENDORFF, Marek - Lithostratigraphy of Neoproterozoic syn-rift sedimentary megabreccia from Mwambashi, Copperbelt of Zambia, and correlation with olistostrome succession from Mufulira. South African Journal of Geology; v. 108; no. 4; p. 505-524; DOI: 10.2113/108.4.505 December 2005. 